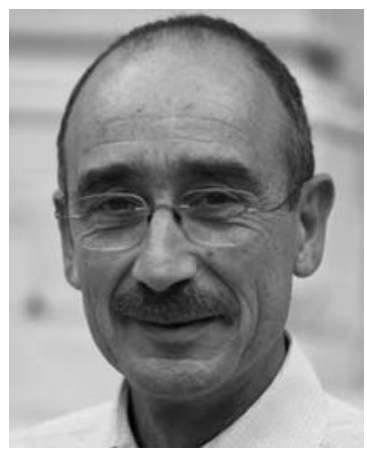

\title{
A Conversation with Denis Duboule
}

\author{
INTERVIEWER: JIAYING TAN \\ Scientific Editor, Cell
}

Denis Duboule is Chair of the Department of Genetics and Evolution at the University of Geneva and a Professor of Developmental Genetics and Genomics at the École Polytechnique Fédérale de Lausanne.

Jiaying Tan: Your work on Hox gene loci made a tremendous contribution to our understanding of embryonic development. How did you start working on this locus?

Dr. Duboule: Here in Cold Spring Harbor, the 50th Anniversary Symposium in 1985 reported some really great discoveries. The homeobox had just been discovered, and all the leading Drosophilists like Ed Lewis and Christiane Nüsslein-Volhard and Eric Wieschaus were there. That was the real start of molecular developmental biology. At that time, I was a postdoc in Pierre Chambon's lab in Strasbourg. He sent me to this meeting to see what was going on and when I came back to Europe I was full of energy and decided to start in this field. Soon after, we managed to clone these genes in mammals with different laboratories-Peter Gruss, Edoardo Boncinelli, Eddy De Robertis - and that's how it started.

Jiaying Tan: You've spent many years working on the Hox gene loci. Where do you see the field moving?

Dr. Duboule: The Hox gene system is interesting in terms of its epistemic value - that is, the number of fundamental advances and concepts that people have learned by using this biological object. Ever since Ed Lewis' work in the 1960s and 70s with flies, the work on mouse Hox genes has largely contributed to the way we look at vertebrate development nowadays. I anticipate that this epistemic value will persist as we go further into new areas of developmental biology. For example, looking at the effects of genome topology and chromatin organization upon gene regulation is a new field of research that has opened in the past five years. Does the structure of the genome influence gene regulation? If it does, how does it change during development? What signals are givennot by genes acting in trans or in cis, but by the entire structure - on gene regulation? This is the sort of question that we can still answer using the Hox gene system as a paradigm.

Jiaying Tan: There are many different kinds of regulation involved for Hox loci. They're in cis, in trans;
lncRNA (long noncoding RNA) are also involved. Different loci cooperate, and now there is the whole concept of TAD (topologically associating domain) structure. Can we distinguish how these different layers of regulation collaborate?

Dr. Duboule: In mammals, the Hox system is controlled both by classical local cis-acting regulations, located very close to the various promoters, but also by very long-range regulations, exerted by enhancers located far away. All the concepts we have inherited from genetics over the past century can be crystallized around the Hox system.

Jiaying Tan: The development of limb systems seems to be one of the best understood at this point. Do you think it will help us answers other questions in development?

Dr. Duboule: To understand development in molecular terms, one needs to have enough biological material. Embryos are notoriously small and it is extremely difficult to get enough tissue from the major body axis, because gastrulation occurs early on in the mammalian embryo. The limb is special in this respect in that it's easier to get developing tissues, which in a way reproduce all fundamental aspects of development. This is why, historically, the knowledge of the limb system has developed rapidly. I'm confident though that by improving the biochemical tools, it's going to be feasible in the next five years to understand the complex and coordinated Hox regulation in the trunk to the level of precision it is now understood in the limbs.

Jiaying Tan: Would you expect similar rules to apply?

Dr. Duboule: I cannot imagine that the rules would be completely different. François Jacob, who was actually here in CSH for the 1985 meeting, emphasized that Nature has constantly reshuffled things during evolution. I would certainly not expect the rules to be completely different, but, on the other hand, it's probable that when the limb appeared in the course of evolution some modifications of the underlying mechanics occurred to be 
better adapted for limbs. There might be slight differences, but I guess the fundamental mechanisms will be the same.

Jiaying Tan: The terminology that was used in the past was "developmental genetics," but now it's more about "developmental genomics." Do you think that just reflects the technical advances, or is it more than that?

Dr. Duboule: No, it has changed a lot. Words are very important in science; they tell you what is happening. In 30 years, we've moved from classical developmental biology, like cutting embryos into pieces to see what would happen, to molecular developmental biologylooking at how a particular gene behaves. Now we are looking at how entire genomes react when we manipulate them. It's a brand new field that only started 5 to 10 years ago but it's a very difficult one because, again, to run biochemistry or genomics on small embryos you need to collect enough material. We'll have to significantly decrease the amount of material required before we can really apply the techniques of genomics to the field of developmental biology, but I think that will be of the key discipline for the next few years.

Jiaying Tan: Do you think the insights we'll get from developmental genomics will just provide greater detail of what's happening in the temporospatial setting or will it be more of an overview of what's happening in developmental processes?

Dr. Duboule: When you start looking at genomes instead of looking at genes, you immediately go to a level that is immensely more complex. I anticipate we're not going to simply find more of the same or minor details. I am absolutely convinced that we still do not understand most of what is happening. Unlike some of my colleagues who think that we have discovered everything and that it's just a matter of filling in a few details, I think we only know a few details and the problem is to really understand the basic mechanisms, the basic principles, the underlying logic and its progressive appearance over evolution. I think that's the challenge for the next 20 years.

The biggest question for me would be to understand the genotype-to-phenotype relationship, the nature of the coding system. How can we encode ourselves in our
DNA? I can understand how a liver works, how to make an enzyme and so on, but how can we encode in our DNA the way to produce ourselves? How does the DNA know how to make an embryo and have it develop? I dream of having a sort of mathematical equation, or perhaps even two or three equations, that would explain how to start with a genome and end up with a fully functional organism.

Jiaying Tan: People always talk about how similar a system is relative to mammalian or other systems. What do you think of people working on developmental questions in different model organisms?

Dr. Duboule: This is another fantastic aspect of developmental biology. Over the past 20 years, we've all come to work within the conceptual framework of evolution. If you talk to scientists, you realize that they integrate their thinking and their data within an evolutionary framework. We now have access to any kind of genome. You can pick any new organism and sequence it. That not only brings new data sets, but it also changes the mind-sets of people working in this field to a more comparative view. Developmental biology brought evolution back into the game in much the same way paleontology did in the last century.

Jiaying Tan: There's been a big technical boom in the field with the introduction of CRISPR and genome editing and new imaging techniques. How do these contribute to our understanding of developmental biology?

Dr. Duboule: Technologies do not really replace technologies. They add to them. I see the emergence of approaches using CRISPR - Cas9-which are now implemented in every laboratory, including mine - not only as a way to produce novel mutations but also to add to existing alleles leading to a next-generation genetics. This new way to edit genomes may help us to see what is happening at the level of transcription during development, but the basic questions don't change. It's important to realize that new technologies help us solve existing questions, but they rarely ask new ones. We really must concentrate on asking the right questions and only then make sure that the technology we select, new and exciting or not, will help us answer them. 


\section{$\$_{\text {CSH }}^{\infty}$ Cold Spring Harbor Symposia SYMPOSIA On Quantitative Biology}

\section{A Conversation with Denis Duboule}

Cold Spring Harb Symp Quant Biol 2015 80: 316-317

Access the most recent version at doi:10.1101/sqb.2015.80.029991

\section{License}

Email Alerting Receive free email alerts when new articles cite this article - sign up in Service the box at the top right corner of the article or click here. 